\title{
UNAMBIGUOUS TEST FOR LINKAGE OF GENES DISPLAYING NON- ALLELIC INTERACTIONS FOR A METRICAL TRAIT
}

\author{
J. L. JINKS \\ Department of Genetics, University of Birmingham, Birmingham B15 2TT
}

Received 29.vii.77

\section{SUMMARY}

A simple statistical test of the equality of the means of $B_{1}, B_{2}$ and $F_{2}$ families and the means of the corresponding $\mathrm{L}_{1}, \mathrm{~L}_{2}$ and $\mathrm{L}_{3}$ generations of an $\mathbf{F}_{2}$ triple testcross is described which specifically detects linkage between genes displaying non-allelic interactions in the presence of other complex effects. The test is used to confirm that linked interacting genes contribute to the variation in final height and flowering time in the cross between varieties 1 and 5 of Nicotiana rustica.

\section{INTRODUGTION}

Perkins AND Jinks (1970) have described an unambiguous test for linkage, which is independent of the presence of non-allelic interactions and genotypeenvironmental interactions, based upon comparisons between the variances of $B_{1}, B_{2}$ and $F_{2}$ families derived from a cross between two pure-breeding lines and those of the $\mathrm{L}_{1}\left(\mathrm{~F}_{2} \times \mathrm{P}_{1}\right), \mathrm{L}_{2},\left(\mathrm{~F}_{2} \times \mathrm{P}_{2}\right)$ and $\mathrm{L}_{3}\left(\mathrm{~F}_{2} \times \mathrm{F}_{1}\right)$ generations of an $F_{2}$ triple test-cross (Kearsey and Jinks, 1968). By extending the same principle to the corresponding family and generation means, linkage of genes displaying non-allelic interactions can be detected unambiguously in the presence of other complex effects.

\section{THEORY}

In the absence of linkage, the expected mean and variance of a $B_{1}$ family and an $L_{1}$ generation, a $B_{2}$ family and an $L_{2}$ generation and an $F_{2}$ family and $\mathrm{L}_{3}$ generation from the the same initial cross are identical irrespective of the presence of non-allelic interactions of any degree of complexity or of genotype-environmental interactions (Jinks and Perkins, 1969; Perkins and Jinks, 1970; Mather and Jinks, 1971). In the presence of linkage the expected variances are no longer the same (Perkins and Jinks, 1970) but the expected means are still the same unless the linkage is between pairs of genes which are also displaying non-allelic interactions (Jinks and Perkins, 1969). In the latter circumstances the three pairs of family and generation means and their differences have the expectations

$$
\begin{aligned}
\bar{B}_{1}=m+\frac{1}{2}[d]+\frac{1}{2}[h]+\frac{1}{2}[i]+\frac{1}{2}[l]-\frac{1}{2}[p i] & +\frac{1}{2}[p j]-\frac{1}{2}[p l] \\
\bar{L}_{1}=m+\frac{1}{2}[d]+\frac{1}{2}[h]+\frac{1}{2}[i]+\frac{1}{2}[l]-\frac{3}{4}[p i] & +\frac{1}{2}\left[p^{2} i\right]+\frac{3}{4}[p j] \\
& -\frac{1}{2}\left[p^{2} j\right]-\frac{3}{4}[p l]+\frac{1}{2}\left[p^{2} l\right]
\end{aligned}
$$


and

$$
\begin{aligned}
& \bar{B}_{1}-\bar{L}_{1}=\frac{1}{4}([p(1-2 p) i]-[p(1-2 p) j]+[p(1-2 p) l]) \\
& \bar{B}_{2}=m-\frac{1}{2}[d]+\frac{1}{2}[h]+\frac{1}{2}[i]+\frac{1}{2}[l]-\frac{1}{2}[p i]-\frac{1}{2}[p j]-\frac{1}{2}[p l] \\
& \bar{L}_{2}=m-\frac{1}{2}[d]+\frac{1}{2}[h]+\frac{1}{2}[i]+\frac{1}{2}[l]-\frac{3}{4}[p i]+\frac{1}{2}\left[p^{2} i\right]-\frac{3}{4}[p j] \\
&+\frac{1}{2}\left[p^{2} j\right]-\frac{3}{4}[p l]+\frac{1}{2}\left[p^{2} l\right]
\end{aligned}
$$

and

$$
\begin{aligned}
\bar{B}_{2}-\bar{L}_{2} & =\frac{1}{4}([p(1-2 p) i]+[p(1-2 p) j]+[p(1-2 p) l]) \\
\bar{F}_{2} & =m+\frac{1}{2}[h]+\frac{1}{2}[i]+\frac{1}{2}[l]-[p i]-[p l]+\left[p^{2} l\right] \\
\bar{L}_{3} & =m+\frac{1}{2}[h]+\frac{1}{2}[i]+\frac{1}{2}[l]-\frac{5}{4}[p i]+\frac{1}{2}\left[p^{2} i\right]-\frac{5}{4}[p l]+2\left[p^{2} l\right]-\left[p^{3} l\right]
\end{aligned}
$$

and

$$
\bar{F}_{2}-\bar{L}_{3}=\frac{1}{4}\left([p(1-2 p) i]+\left[p(1-2 p)^{2} l\right]\right)
$$

(see Jinks and Perkins (1969) for definition of symbols).

It is clear from these expectations that there are only two conditions under which $\bar{B}_{1}=\bar{L}_{1}, \bar{B}_{2}=\bar{L}_{2}$ and $\bar{F}_{2}=L_{3}$; these are, no non-allelic interactions $(i=j=l=0)$ or no linkage $\left(p=\frac{1}{2}\right)$. The null hypothesis tested by comparing these pairs of means is, therefore, specifically the absence of linkage between genes displaying non-allelic interactions.

This is true irrespective of how far we complicate these expectations by including higher order non-allelic interactions and genotype-environmental interactions.

\section{EXAMPLE}

Jinks and Perkins (1969) using sequential weighted least squares model fitting procedures on the means of 21 generations derived from a cross between varieties 1 and 5 of Nicotiana rustica concluded that a model containing linkage between pairs of genes displaying non-allelic interactions (linked digenic interactions) was adequate for final height but that one which also included higher order interactions (e.g. trigenic interactions) was probably more satisfactory for flowering time. These conclusions were based upon the relative improvements in goodness of fit of models incorporating linkage between pairs of interacting genes (linked digenic interactions) on the one hand, and higher order interactions among unlinked genes (trigenic interactions) on the other, to data where a digenic interaction model without linkage was inadequate. Since $\mathrm{B}_{1}, \mathrm{~B}_{2}, \mathrm{~F}_{2}$ families and $\mathrm{L}_{1}\left(\mathrm{~F}_{2} \times \mathrm{P}_{1}\right)$, $\mathrm{L}_{2}\left(\mathrm{~F}_{2} \times \mathrm{P}_{2}\right), \mathrm{L}_{3}\left(\mathrm{~F}_{2} \times \mathrm{F}_{1}\right)$ generations were included among the 21 generations of this cross an unambiguous test for linked interacting genes is now possible. The data for final height and flowering time are summarised in tables 1 and 4 of Jinks and Perkins (1969). For final height:

$$
\begin{array}{ll}
\bar{B}_{1}-\bar{L}_{1}=-0.57 \pm 0.52 & (\mathrm{P}>0.05) \\
\bar{B}_{2}-\bar{L}_{2}=-0.14 \pm 0.50 & (\mathrm{P}>0.05) \\
\bar{F}_{2}-\bar{L}_{3}=-1.69 \pm 0.46 & (\mathrm{P}<0.001)
\end{array}
$$


and for flowering time:

$$
\begin{array}{ll}
\bar{B}_{1}-\bar{L}_{1}=-1.29 \pm 0.38 & (\mathrm{P}<0.001) \\
\bar{B}_{2}-\bar{L}_{2}=-0.24 \pm 0.39 & (\mathrm{P}>0.05) \\
\bar{F}_{2}-\bar{L}_{3}=-1.80 \pm 0.38 & (\mathrm{P}<0.001)
\end{array}
$$

As each family or generation mean is based on between 160 and 400 individually randomised plants the ratio of these deviations to their standard deviations are normal deviates (c).

One of the three comparisons for final height and two of the three comparisons for flowering time are highly significantly different from zero. There is strong evidence, therefore, of linkage between interacting genes for both characters. This result confirms in a more direct way the conclusions from our earlier model fitting. At the same time it illustrates once more a point we have repeatedly made (see, for example, Perkins and Jinks, 1970; Eaves, Last, Martin and Jinks, 1977) namely, that simple statistical tests (scaling tests) are in general more sensitive and more specific than sequential model fitting procedures for detecting complex effects such as linkage, nonallelic interactions and genotype-environmental interactions and correlations when simpler models or even all models fail. They should be used, therefore, wherever possible as a preliminary to model fitting to determine the level of complexity of the model that is required. The role of model fitting is then properly the estimation of the parameters in the model.

\section{RefERENCES}

EAVES, L. J., LAST, K. A., MARTiN, N. G., AND JiNks, J. L. 1977. A progressive approach to non-additivity and genotype-environmental covariance in the analysis of human differences. Br. F. Math. Statist. Psychol., 30, 1-42.

JINKs, J. L., AND PERKINS, J. M. 1969. The detection of linked epistatic genes for a metrical trait. Heredity, 24, 465-475.

KEARSEY, M. J., AND JINKS, J. L. 1968. A general method of detecting additive, dominance and epistatic variation for metrical traits. I. Theory. Heredity, 23, 403-410.

MATHER, K., AND JINKs, J. L. 1971. Biometrical Genetics, 2nd Edition. Chapman and Hall, London.

PERKINS, J. M., AND JINKS, J. L. 1970. Detection and estimation of genotype-environmental, linkage and epistatic components of variation for a metrical trait. Heredity, 25, 157-177. 